\title{
Bem-Estar no Trabalho: o Impacto das Satisfações com os Suportes Organizacionais e o Papel Mediador da Resiliência No Trabalho
}

Well-Being at Work: the Impact of Satisfaction with Organizational Supports and the Mediating Role of Resilience at Work

» Sinésio GOMIDE Júnior (Universidade Federal de Uberlândia, Brasil)

» Luiz Humberto Bonito SILVESTRIN (Universidade Federal de Uberlândia, Brasil)

» Áurea de Fátima OLIVEIRA (Universidade Federal de Uberlândia, Brasil)

Resumo O bem-estar no trabalho tem ganhado bastante visibilidade na literatura concernente à área da psicologia organizacional e do trabalho pela sua importância como variável que, se bem compreendida, pode conferir aos trabalhadores melhores condições de trabalho e até de vida.

Este trabalho tem por objetivo principal testar o poder mediacional da resiliência no trabalho na relação entre as satisfações com os suportes organizacionais e o bem-estar no trabalho. $\mathrm{O}$ modelo testado não se confirmou e as hipóteses explicativas foram levantadas juntamente a uma agenda de pesquisas.

Palavras-chave:

bem-estar no trabalho; suportes organizacionais; resiliência.

Abstract Well-being at work has gained visibility in the literature regarding organizational and work psychology due to its importance as a variable which - if well understood - is able to provide workers not only with better working conditions but also better life conditions. The main aim of this work is to test the mediating power of resilience at work in the relation between the satisfaction with organizational supports and well-being at work. The model tested hasn't been confirmed, and explanatory hypotheses have been raised along with a research agenda.

Keywords:

well-being at work; organizational supports; resilience.

Resumen El bienestar en el trabajo ha venido ganando visibilidad en la literatura que concierne al área de comprendida, puede proporcionar a los trabajadores mejores condiciones de trabajo y hasta de vida. Este trabajo tiene como objetivo principal comprobar el poder de mediación de la resiliencia en el trabajo en la relación entre la satisfacción con los soportes organizacionales y el bienestar en el trabajo. El modelo puesto a prueba no se confirmó y algunas hipótesis explicativas fueron consideradas en conjunto con una agenda de investigación. Palabras-clave:

Bienestar en el trabajo; Soportes Organizacionales; Resiliencia 
A

organização geralmente é definida pelo modo como seus processos são estruturados e gerenciados desenho do trabalho, gerenciamento, características organizacionais, políticas e procedimentos. Hernandez (2007) defende que, inerente a esta definição, está a ideia de que a estrutura e o funcionamento de uma organização podem ter um grande impacto na saúde e no bem-estar de seus empregados, que, por sua vez, têm impacto na efetividade da organização como um todo.

Mudanças recentes no ambiente de trabalho (fusões, privatizações, terceirização, entre outras) exigiram do trabalhador diversos tipos de adaptações, como a dependência da tecnologia e a flexibilidade de atividades e competências. Essa perspectiva tem levado pesquisadores e profissionais a buscar formas de propiciar a saúde e o bem-estar dos indivíduos no ambiente de trabalho (Jaffe, 1995) que, conforme Hernandez (2007), têm sido historicamente abordados pela literatura sob um enfoque dos fatores comprometedores dessas variáveis, explorando o estresse e o sofrimento dos trabalhadores.

Contudo, novas perspectivas têm sido buscadas, destacando-se a de se investigar aspectos positivos do ambiente de trabalho. Inicialmente proposto por Maslow (1954), o conceito de psicologia positiva foi resgatado e consolidado por Seligman e Csikszentmihalyi (2000). A psicologia positiva tem por objetivo a mudança de foco: sua preocupação é reparar os desvios estruturais ou individuais para aquele cujo enfoque é a construção de características positivas e o entendimento das condições que promovem a saúde e a prosperidade humana.

Pesquisadores dessa linha acreditam que a presença de estados emocionais e avaliações positivas dos trabalhadores e sua relação com o ambiente de trabalho aumentam a qualidade de vida e o desempenho (Harter, Schmidt, \& Keyes, 2002).

Essas características positivas podem se referir ao indivíduo, como os conceitos de bem-estar no trabalho (Mendonça, Ferreira, Porto, \& Zanini, 2012; Siqueira \& Padovam, 2008), ou à organização, como o conceito de saúde organizacional (Bennis, 1962; Gomide \& Nascimento, 2012; Jaffe, 1995).

A perspectiva teórica da psicologia positiva embasa este estudo, que objetiva investigar antecedentes do bem-estar no trabalho, ainda não focalizados pela literatura, em um escopo detalhado a seguir.

\section{BEM-ESTAR NO TRABALHO}

Conforme postulam Ferreira, Souza e Silva (2012), a pesquisa voltada para a análise das relações entre trabalho e bem-estar do empregado teve como foco inicial os impactos negativos. Ainda conforme as autoras, a literatura sobre o bem-estar no trabalho tem obtido avanços consideráveis a partir da pressuposição de que o mal-estar e o bem-estar consistem em construtos distintos, ainda que relacionados, sendo possuidores de antecedentes e consequentes diversos.

As pesquisas sobre bem-estar no trabalho não são conclusivas acerca de sua conceituação, o que tem gerado inúmeras definições e modelos conceituais ou explicativos. Ferreira, Souza e Silva (2012) citam quatro modelos atuais que, presentes na literatura, confirmam o pouco consenso existente entre os autores que estudam essa temática.

No primeiro modelo, de 2004, Van Horn, Taris, Schaufeli e Schreursapresentam o bem-estar ocupacional como um conceito multidimensional associado à avaliação positiva de características afetivas, motivacionais, comportamentais, cognitivas e psicossomáticas inerentes ao ambiente de trabalho. O segundo modelo citado pelas autoras é o de De Joy e Wilson que, em 2003, consideraram o bem-estar no trabalho composto por aspectos físicos, mentais e emocionais que agem de forma sinérgica. O terceiro modelo (Ferreira, Souza, \& Silva, 2012) é o de Schulte e Vainio, de 2010, que defenderam ser o bem-estar no trabalho composto pela percepção da qualidade de vida nesse ambiente. Para esses autores, a percepção da qualidade de vida no trabalho reflete a satisfação do empregado com seu trabalho e sua vida em geral. Siqueira e Padovam (2008), no quarto modelo citado, sustentam que o bem-estar no trabalho consiste em um construto psicológico associado aos vínculos afetivos positivos que o empregado mantém com seu trabalho e sua organização.

As autoras (Ferreira, Souza, \& Silva, 2012) concluem que as conceituações para o bem-estar no trabalho presentes na literatura têm variado de concepções amplas e multidimensionais, que abarcam aspectos cognitivos, afetivos, comportamentais e físicos, a concepções mais restritas, normalmente unidimensionais, que se utilizam apenas da dimensão afetiva do construto.

A preocupação com o bem-estar no ambiente de trabalho é um tema recorrente em estudos acadêmicos e literaturas especializadas no contexto organizacional (Hernandez, 2007), notadamente por suas consequências na própria qualidade de vida do trabalhador, como na produtividade (ou efetividade) organizacional. 
Keyes, Hysom e Lupo (2000) postulam que, à medida que o bem-estar do trabalhador aumenta, a produtividade e a lucratividade da organização tendem também a um incremento. Afirmam, ainda, ser recíproca a influência entre estes fatores, ou seja, o bem-estar do trabalhador afeta os resultados da organização, que também podem ser um dos causadores do bem-estar.

Harter, Schmidt e Keyes (2002), reforçando a ideia da relação entre bem-estar no trabalho e resultados organizacionais positivos, relatam, por exemplo, que maiores níveis de satisfação com o ambiente de trabalho, desenvolvimento pessoal por meio da atividade e relações amistosas no trabalho estão positivamente relacionados a níveis mais altos de lealdade, lucratividade, produtividade e retenção.

Quanto aos fatores que determinariam o bem-estar no trabalho, os estudos também têm sido profícuos. Segundo Ferreira (2012), o estudo do papel exercido pelas diferenças individuais ou disposicionais sobre o bem-estar no trabalho tem uma longa tradição na psicologia. Até pouco tempo, porém, a maioria desses estudos orientava-se pelo marco conceitual do estresse no trabalho, de modo congruente com o modelo de doença que por longo tempo predominou na psicologia, conforme já apontado anteriormente. Alinhadas com tal orientação, essas investigações focalizavam-se prioritariamente na análise dos traços que predispunham os trabalhadores a vivenciarem o estresse no trabalho, operacionalizado por meio de indicadores de depressão, de ansiedade e de insatisfação no trabalho.

Conforme Rocha Sobrinho e Porto (2012), o bem-estar no trabalho tradicionalmente tem sua conceituação tratada conforme dois enfoques. O primeiro como uma manifestação ou avaliação afetiva das características do trabalho, cujo ponto central seria o balanço, ou equilíbrio, entre as avaliações positivas e negativas feitas pelo indivíduo. Se o balanço for positivo, fica evidenciado o bem-estar; se negativo, é constatada sua ausência. Esse primeiro enfoque aproxima-se da conceituação de bem-estar subjetivo, sendo baseado nele. O segundo enfoque, conforme Rocha Sobrinho e Porto (2012), trata o bem-estar no trabalho como um conjunto de avaliações positivas sobre seus aspectos, como motivação, ambientação, remuneração e outros.

Ainda conforme os autores, não há como negar que, embora o afeto seja uma questão central nos estudos sobre bem-estar no trabalho, as percepções que o indivíduo tem sobre os aspectos relacionados ao trabalho podem constituir-se como predisponentes às avaliações afetivas. Portanto, elas devem ser consideradas como parte integrante da própria conceituação de bem-estar. Esse enfoque tem como pano de fundo as proposições conceituais de bem-estar psicológico, se assentando nele.

Há, ainda, um terceiro enfoque, que trata o bem-estar no trabalho como sinônimo de qualidade de vida no trabalho, não fazendo distinção entre os termos. Nele, a qualidade de vida no trabalho é investigada pelas avaliações positivas duradouras que o empregado faz de aspectos de seu trabalho e de sua organização. Nesse enfoque, a qualidade de vida no trabalho é definida como o balanço entre vivências positivas (bem-estar no trabalho) e vivências negativas (mal-estar no trabalho), o que caracterizaria a boa qualidade de vida no trabalho (se vivências positivas prevalecessem) ou a má qualidade de vida no trabalho (o oposto) (Ferreira, 2012).

Neste trabalho, será empregada a conceituação proposta por Paz (2011) e Paz, Neiva e Dessen (2012), segundo a qual bem-estar no trabalho - ou bem-estar pessoal nas organizações - é definido como a satisfação de necessidades e a realização de desejos dos indivíduos no desempenho de seu papel organizacional, apresentando dois polos: a gratificação e o desgosto. Dessa proposição, que abarca aspectos do bem-estar subjetivo e do bemestar psicológico, derivou o instrumento de medida (Paz, 2005) utilizado neste estudo.

\section{Antecedentes do bem-estar no trabalho}

Em um estudo recente, Sant'anna, Paschoale Gosendo (2012) afirmaram que diversas pesquisas têm apontado diversas variáveis que confirmaram ser preditoras do bem-estar no trabalho, como oportunidades de controle, autonomia, sobrecarga de trabalho, percepções de justiça, configurações de poder e suporte organizacional. As autoras afirmaram, ainda, que a sistematização dos achados é uma tarefa bastante complexa, dado que as pesquisas abarcam definições e operacionalizações do construto de forma bastante variada. Contudo, apontam que as pesquisas são mais afeitas à investigação de emoções negativas do que positivas, e que pesquisas que investigam a realização pessoal do trabalhador são bem mais escassas. Gomide Jr. e Hernandez, em 2005, já apontavam que aspectos ou avaliações relativas ao trabalho, quando comparadas às avaliações relativas à vida pessoal do indivíduo, tinham maior poder de predição sobre o bem-estar no trabalho, notadamente quando era utilizado o conceito proposto por Siqueira e Padovan (2008). Gomide e Hernandez (2005) relatam como 
preditores bastante consistentes a percepção de suporte organizacional e as percepções de suportes sociais no trabalho, sendo o primeiro fator superior ao segundo.

Soraggi e Paschoal (2012), por outro lado, confirmam a importância, para pesquisadores e gestores, de se investigar a interação entre variáveis pessoais e organizacionais presentes na própria ambientação de trabalho. As autoras justificam essa premissa afirmando que aspectos da realização no trabalho podem depender dessa interação, além de serem pouco investigados.

Com base nessa perspectiva, aparece como importante construto a ser pesquisado como antecedente do bemestar no trabalho a noção de resiliência, que resultou de estudos que procuraram focalizar aspectos saudáveis dos indivíduos, conferindo-lhes um caráter de ajustamento e adaptação ao longo de seu desenvolvimento. Assim, é possível inserir o interesse pelo estudo da resiliência como um dos fenômenos indicativos de uma vida saudável em virtude de sua contemplação de comportamentos mais adequados à sobrevivência do indivíduo.

Definida por Batista e Oliveira (2008) como a capacidade (percebida pelo indivíduo) de lidar com problemas de forma proativa, autônoma e determinada, buscando alternativas juntamente com a confiança em si mesmo, a resiliência tem sido apontada como importante preditor de adaptação a condições adversas de vida, felicidade e recuperação a situações traumáticas (Batista \& Oliveira, 2008). Esse estudo enfatiza a resiliência como característica motivacional do ser humano. No entanto,, a ideia de utilizar o conceito de resiliência no trabalho não é recente (Day \& Gu, 2007; Job, 2003).

Em 2008, Barlach, Limongi-França e Malvezzi cunharam o termo "resiliência no trabalho" quando investigaram estresse e coping em executivos e alunos de cursos de educação continuada, ressaltando que a resiliência no trabalho decorre da capacidade individual de ressignificação de situações adversas. Os estudos reafirmam a resiliência como uma variável individual, ligada à resistência em superar situações adversas (no trabalho ou fora dele).

Medidas de resiliência aplicadas ao contexto organizacional têm sido utilizadas em trabalhos no Brasil e no exterior (Carvalho, Borges, Vikan, \& Hjemdal, 2011; Hjemdal, Roazzi, Dias, Roazzi, \& Vikan, 2009), porém, medidas do construto "resiliência no trabalho" são raras. Foi encontrada apenas a de Lopes e Martins (2011), adaptada para o Brasil a partir da escala $C D-R I S C$-10 de Connor e Davidson, publicada originalmente em 2003, nos Estados Unidos. No Brasil, foram encontrados dois trabalhos que testaram o emprego do conceito de resiliência em condições laborais. No primeiro, Batista e Oliveira (2012) compararam o índice de determinação de resiliência e de percepção de suporte organizacional na predição da confiança do empregado na organização. Encontraram que a percepção de suporte organizacional é a melhor preditora da variável critério investigada em comparação à autodeclaração de resiliência.

No segundo trabalho, Martins, Siqueira, Pieroni e Zampieri (2012) concluíram que as percepções de suporte organizacional, suporte social no trabalho e afetos positivos e negativos no trabalho não predisseram níveis de resiliência relatados em trabalhadores. As autoras concluíram, como a literatura já havia relatado, que as variáveis de cunho individual são preditoras frágeis para critérios relacionados ao trabalho e às organizações.

Conforme pesquisas relacionadas, o bem-estar no trabalho tem como antecedentes variáveis de cunho individual e organizacional e cunho cognitivo e afetivo. Pesquisas também têm demonstrado a prevalência de variáveis de caráter organizacional sobre aquelas de caráter individual. Dessa forma, parece razoável supor que resiliência no trabalho seja um bom preditor de bem-estar no trabalho. Parece ainda mais provável supor que resiliência no trabalho, aliada a variáveis de caráter afetivo, seja mais consistente como antecedente de bem-estar. De modo consensual, avaliações afetivas sobre aspectos do trabalho têm sido apontadas como fortes preditoras de bem-estar no trabalho.

Neste estudo, diante das evidências da literatura, testou-se a hipótese de que avaliações (positivas) dirigidas a aspectos do trabalho, quando mediadas pela percepção individual de resistência a aspectos negativos deste mesmo trabalho, seriam fortes e consistentes preditoras de bem-estar no trabalho. Assim, este estudo teve como objetivo testar um modelo preditivo para bem-estar no trabalho inédito na literatura, consideradas as avaliações sobre os suportes organizacionais (organizacional e social) como antecedentes mediados pela resiliência no trabalho. A Figura 1 sintetiza o modelo hipotético testado. 


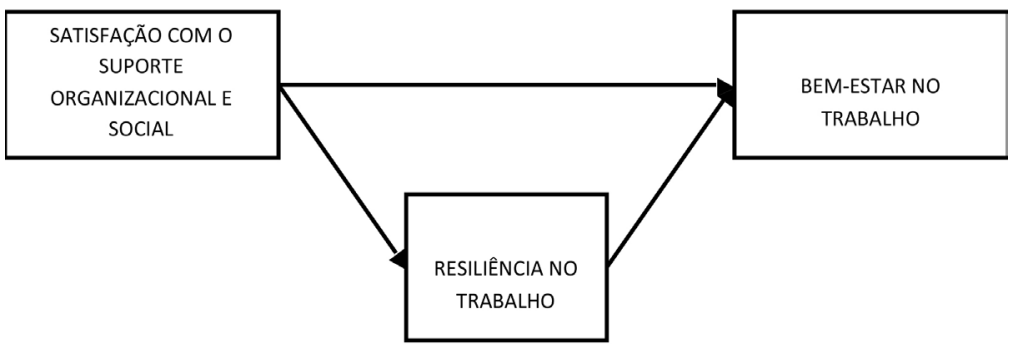

FIGURA 1. Modelo hipotético proposto para investigação

Para o alcance deste objetivo, foram realizados três estudos. O primeiro buscou evidências de validação de uma escala de percepção de resiliência no trabalho; o segundo investigou essas evidências em um instrumento de satisfação com o suporte organizacional e um instrumento de satisfação com os suportes sociais no trabalho; e o terceiro estudo testou a mediação entre as satisfações com os suportes organizacionais e a resiliência no trabalho na explicação do bem-estar no trabalho. Os três estudos e seus achados são relatados a seguir.

\section{OS ESTUDOS DE RESILIÊNCIA, SUPORTES ORGANIZACIONAIS E BEM- ESTAR NO TRABALHO}

O primeiro estudo teve como objetivo validar um instrumento de medida para resiliência no trabalho. Para isso, o instrumento de medida de resiliência construído e validado por Batista e Oliveira (2008) foi adaptado para situações relativas ao trabalho. O instrumento adaptado foi respondido por 164 trabalhadores formalmente empregados em organizações do Triângulo Mineiro, que completaram, pelo menos, o ensino fundamental, constituindo uma amostragem por conveniência, sendo 59,8\% do sexo feminino, com 1,8\% de dados ausentes. O nível de escolaridade variou do ensino fundamental completo à pós-graduação, predominando os participantes com curso superior incompleto e completo (51,9\%). A amostra apresentou idade média de 31,05 anos ( $\mathrm{DP}=9,8$ anos), variando entre 18 e 63 anos, e tempo médio de trabalho na organização de 4,7 anos (DP= 6,4 anos).

Para análise dos dados nos três estudos, utilizou-se o programa estatístico SPSS (Statistical Package of Social Science), versão 19.0 Foi realizada uma análise exploratória dos dados com o objetivo de verificar a precisão do arquivo de dados. Foram detectados poucos dados omissos e sua distribuição foi aleatória, não havendo, portanto, um padrão. Como o maior percentual de dados ausentes foi de 5\%, optou-se pela substituição pela média da resposta do grupo. Os outliers univariados foram identificados mediante verificação do gráfico boxplot, e a inspeção visual indicou casos univariados moderados em diversas variáveis. Casos extremos multivariados foram identificados por meio da distância de Mahalanobis com $\chi^{2}=37,697$; gl= 15 e $\mathrm{p}<0,001$. Quatorze casos apresentavam-se superiores ao valor estabelecido, sendo, portanto, eliminados da amostra, o que resultou nos 164 casos que compuseram a amostra final.

Para verificar a estrutura fatorial do instrumento, foram realizadas análises dos componentes principais (PC) e análise dos eixos principais (PAF/oblimin) para confirmação da estrutura fatorial (cargas iguais ou superiores a 0,40; autovalores iguais ou superiores a 1,5). A configuração final do instrumento foi de uma medida unifatorial, composta por 15 itens, com cargas entre 0,43 e 0,77 e confiabilidade (Alpha de Cronbach) de 0,87 (KMO igual a 0,869).

TABELA 1. Composição dos fatores, variâncias explicadas, valores próprios, cargas fatoriais dos itens e "Alpha de Cronbach" do fator único do instrumento de resiliência no trabalho (Escala de 7 pontos: de 1) discordo totalmente a 7) concordo totalmente).

\begin{tabular}{lr}
\hline Itens & Fator único \\
No meu trabalho... & 0,77 \\
Mantenho interesse nele. & 0,66 \\
Quando estou em uma situação difícil, normalmente acho uma saída. & 0,65 \\
Tenho energia suficiente para fazer o que preciso fazer. & 0,65 \\
Sou determinado. & 0,44 \\
Posso olhar normalmente para uma situação de diversas maneiras. & 0,42 \\
Minha autoconfiança me leva a passar por períodos difíceis. & 0,60
\end{tabular}


Meu trabalho tem sentido para mim.

$\begin{array}{cc}0,59 & 0,35 \\ 0,56 & 0,31 \\ 0,55 & 0,30 \\ 0,53 & 0,29 \\ 0,53 & 0,28 \\ 0,48 & 0,23 \\ 0,47 & 0,22 \\ 0,47 & 0,21 \\ 0,43 & 0,19 \\ 15 & - \\ 5,00 & - \\ 0,87 & - \\ 33,35 & -\end{array}$

Sinto orgulho de ter realizado coisas.

Sou uma pessoa com quem as pessoas podem contar em situações de emergência.

Normalmente posso achar motivos para rir.

0,29

Costumo lidar com os problemas de uma forma ou de outra.

0,28

Quando faço planos, eu os levo até o fim.

0,23

Sou disciplinado.

,22

Manter interesse nas coisas é importante para mim.

0,21

Sou amigo de mim mesmo.

, 19

Número de itens

Autovalores

Percentual de variância explicada

O segundo estudo teve por objetivo adaptar e validar os instrumentos de satisfação com o suporte organizacional percebido e de satisfação com os suportes sociais no trabalho. O primeiro instrumento foi adaptado a partir dos originais de Siqueira (1995), e o segundo a partir de Gomide, Guimarães e Damásio (2004). Eles foram respondidos por 167 trabalhadores formalmente empregados em organizações do Triângulo Mineiro, que completaram, pelo menos, o ensino fundamental, constituindo uma amostragem por conveniência, sendo 59,8\% do sexo feminino, com 3\% de dados ausentes. O nível de escolaridade variou do ensino fundamental completo à pós-graduação, predominando os participantes com pós-graduação (32\%). A amostra apresentou idade média de 31,24 anos ( $\mathrm{DP}=9,86$ anos), variando entre 18 e 63 anos e tempo médio de trabalho na organização de 4,69 anos ( $\mathrm{DP}=6,37$ anos).

Os outliers univariados foram identificados mediante verificação do gráfico boxplot. A inspeção visual indicou casos univariados moderados em diversas variáveis. Casos extremos multivariados foram identificados por meio da distância de Mahalanobis avaliada com qui-quadrado com graus de liberdade igual ao número de variáveis. Com $\chi^{2}=52,620 ; \mathrm{gl}=25$ e $\mathrm{p}<0,001$, dois casos apresentavam-se superiores ao valor estabelecido, sendo, portanto, eliminados da amostra, o que resultou em 167 sujeitos que compuseram a amostra final.

Para verificar a estrutura fatorial dos instrumentos, foram realizadas análises dos componentes principais (PC) e análise dos eixos principais (PAF/oblimin) para confirmação das estruturas fatoriais (cargas iguais ou superiores a 0,40 ; autovalores iguais ou superiores a 1,5). A configuração final do primeiro instrumento (satisfação com o suporte organizacional percebido) foi de uma medida unifatorial, composta por seis itens, com cargas entre 0,67 e 0,86 e confiabilidade (Alpha de Cronbach) de 0,89 (KMO igual a 0,882).

TABELA 2. Composição dos fatores, variâncias explicadas, valores próprios, cargas fatoriais dos itens e "Alpha de Cronbach" do fator único do instrumento de satisfação com o suporte organizacional percebido (Escala de 7 pontos: de 1) totalmente insatisfeito a 7) totalmente satisfeito).

\begin{tabular}{lc}
\hline Itens & Fator único \\
Na empresa onde trabalho, eu estou... & 0,87 \\
$\begin{array}{l}\text {...com a preocupação que a empresa tem com minha satisfação no } \\
\text { trabalho. }\end{array}$ & 0,84 \\
...com a preocupação que a empresa tem com o meu bem-estar. & 0,74 \\
...Com as tentativas da empresa em fazer o meu trabalho ser o mais & 0,81 \\
interessante possível. & 0,81 \\
...com a prontidão da empresa em me ajudar quando eu precisar de um & 0,65 \\
favor especial. & 0,75 \\
...com a ajuda que é possível obter quando tenho um problema. & 0,74 \\
...com a disposição da empresa em ampliar suas instalações para me & 0,54 \\
ajudar a utilizar melhor minhas habilidades. & 6,47 \\
Número de itens & 6 \\
Autovalores & 3,40 \\
Alpha de Cronbach & 0,89 \\
Percentual de variância explicada & 58,36
\end{tabular}


A configuração final do segundo instrumento (satisfação com os suportes sociais no trabalho percebido) foi de uma medida composta por três fatores, sendo o primeiro fator (satisfação com o suporte social informacional percebido) composto por seis itens, com cargas entre 0,45 e 0,775 e confiabilidade (Alpha de Cronbach) de 0,90. O segundo fator (satisfação com o suporte social emocional percebido) foi composto por quatro itens, com cargas fatoriais entre 0,69 e 0,88 e confiabilidade (Alpha de Cronbach) de 0,90. O terceiro fator (satisfação com o suporte social instrumental percebido) foi composto por seis itens, com cargas entre 0,45 e 0,77 e confiabilidade (Alpha de Cronbach) de 0,85. A medida de KMO para esta amostra foi de 0,882.

TABELA 3. Composição dos fatores, variâncias explicadas, valores próprios, cargas fatoriais dos itens e "Alpha de Cronbach" dos fatores de satisfação com os suportes sociais percebidos (Escala de 7 pontos de: 1 ) totalmente insatisfeito a 7) totalmente satisfeito)

\begin{tabular}{|c|c|c|c|c|}
\hline $\begin{array}{l}\text { Itens } \\
\mathrm{Na} \text { empresa onde trabalho, eu sou... }\end{array}$ & Informacional & Emocional & Material & $h^{2}$ \\
\hline $\begin{array}{l}\text {...com a maneira que as pessoas são informadas } \\
\text { sobre as decisões que envolvem o trabalho que } \\
\text { realizam. }\end{array}$ & 0,87 & & & 0,75 \\
\hline $\begin{array}{l}\text {...com a maneira que as informações importantes } \\
\text { para o trabalho são compartilhadas por todos. }\end{array}$ & 0,84 & & & 0,73 \\
\hline $\begin{array}{l}\text {...com a clareza que as informações circulam entre } \\
\text { os setores da empresa. }\end{array}$ & 0,81 & & & 0,68 \\
\hline $\begin{array}{l}\text {...com a agilidade que as informações importantes } \\
\text { para o trabalho são repassadas aos funcionários. }\end{array}$ & 0,80 & & & 0,72 \\
\hline $\begin{array}{l}\text {...com a maneira que os superiores compartilham as } \\
\text { informações importantes com os funcionários. }\end{array}$ & 0,76 & & & 0,67 \\
\hline $\begin{array}{l}\text {...com a facilidade de acesso às informações } \\
\text { importantes. }\end{array}$ & 0,59 & & & 0,61 \\
\hline $\begin{array}{l}\text {...com a maneira que as pessoas demonstram que } \\
\text { gostam umas das outras. }\end{array}$ & & 0,88 & & 0,84 \\
\hline $\begin{array}{l}\text {...com a maneira que as pessoas são amigas umas } \\
\text { das outras. }\end{array}$ & & 0,87 & & 0,80 \\
\hline $\begin{array}{l}\text {...com a maneira que as pessoas confiam umas nas } \\
\text { outras. }\end{array}$ & & 0,73 & & 0,63 \\
\hline $\begin{array}{l}\text {...com a maneira que as pessoas compartilham seu } \\
\text { problemas pessoais umas com as outras. }\end{array}$ & & 0,69 & & 0,53 \\
\hline $\begin{array}{l}\text {...com os equipamentos necessários para os } \\
\text { funcionários realizarem suas tarefas. }\end{array}$ & & & 0,77 & 0,64 \\
\hline ...com as condições de uso dos equipamentos. & & & 0,71 & 0,56 \\
\hline $\begin{array}{l}\text {...com a compatibilidade dos salários aos esforços } \\
\text { dos funcionários. }\end{array}$ & & & 0,70 & 0,63 \\
\hline $\begin{array}{l}\text {...com o cumprimento de suas obrigações financeiras } \\
\text { com seus funcionários. }\end{array}$ & & & 0,54 & 0,32 \\
\hline $\begin{array}{l}\text {...com a ajuda financeira para que seus funcionários } \\
\text { adquiram novos conhecimentos. }\end{array}$ & & & 0,50 & 0,42 \\
\hline $\begin{array}{l}\text {...com a maneira que as pessoas são } \\
\text { recompensadas financeiramente por seus esforços } \\
\text { no desempenho de seus trabalhos. }\end{array}$ & & & 0,45 & 0,50 \\
\hline Número de itens & 06 & 04 & 06 & - \\
\hline Autovalores & 7,7 & 1,5 & 1,3 & - \\
\hline Alpha de Cronbach & 0,93 & 0,90 & 0,85 & - \\
\hline Percentual de variância explicada & 43,09 & 8,70 & 7,33 & - \\
\hline
\end{tabular}

O terceiro estudo foi realizado para testar o poder de mediação da variável resiliência no trabalho sobre a relação entre as variáveis satisfações com os suportes organizacionais percebidos e a variável bem-estar no trabalho.

Para alcançar o objetivo, foi aplicado um questionário contendo os dois instrumentos de medida validados nos estudos um e dois, mais o instrumento de medida de bem-estar no trabalho, construído e validado por Paz, em 2005 (Alpha de Cronbach igual a 0,91). O questionário foi respondido por 159 trabalhadores formalmente empregados em organizações do Triângulo Mineiro, que completaram, pelo menos, o ensino fundamental, constituindo uma amostragem por conveniência, sendo 59,7\% do sexo feminino, com 1,9\% de dados ausentes. $\mathrm{O}$ nível de escolaridade variou do ensino fundamental completo à pós-graduação, predominando os participantes com pós-graduação $(32,1 \%)$. A amostra apresentou idade média de 31,26 anos ( $\mathrm{DP}=9,98$ anos) e tempo médio 
de trabalho na organização de 4,75 anos ( $\mathrm{DP}=6,49$ anos). Os outliers univariados foram verificados através de boxplots.

Nas variáveis relativas a suportes e bem-estar, poucos casos univariados moderados foram identificados. No caso dos itens relativos à resiliência no trabalho, havia outliers extremos, então, a opção foi verificar os outliers multivariados antes de adotar a medida de eliminá-los. Para identificar os casos multivariados, foi calculada a distância de Mahalanobis com $\mathrm{gl}=56$, p<0,001 e $\chi^{2}=86.661$. Foram identificados seis casos, os quais foram eliminados do banco de dados, resultando nos 159 sujeitos que compuseram a amostra final ( $G$ Test - para efeito moderado, níveis de confiança de $95 \%$ e cinco preditores - aponta uma amostra composta de, no mínimo, 139 respondentes).

Antes de realizar as análises de regressões, foi verificada a normalidade da distribuição das variáveis que compunham o modelo proposto para investigação, quando foram considerados os valores de assimetria e de curtose indicados por Miles e Shevlin (2001). Todas as variáveis apresentaram distribuição dentro dos parâmetros da normalidade. A homocedasticidade e a linearidade do modelo de regressão foram analisadas pelos resíduos da regressão. A multicolinearidade foi analisada pelos índices de correlação entre as variáveis, não sendo encontrados índices que impediriam as análises estatísticas. Para esta amostra, também foi testada a confiabilidade dos instrumentos utilizados. O instrumento de medida de bem-estar obteve índice de confiabilidade de 0,90; o de resiliência no trabalho obteve índice de 0,90 e os instrumentos de satisfação com o suporte organizacional, com o suporte social informacional, material e emocional obtiveram índices de 0,89 ; 0,93; 0,85 e 0,90 respectivamente.

Para o teste de mediação, foram realizadas quatro análises de regressão múltipla padrão uma por vez para cada conjunto de variáveis. A caracterização da relação de mediação baseou-se nas quatro condições definidas por Baron e Kenny (1986) e por Ribeiro (2012): 1) a variável antecedente prediz a variável critério de forma significativa; 2) a variável mediadora prediz a variável critério; 3) a variável mediadora de forma significativa; e 4) ao inserir a variável antecedente e a mediadora na equação, a relação entre a variável antecedente e a variável critério, previamente constatada como significativa, decresce em magnitude.

A Tabela 4 sintetiza os resultados encontrados nas quatro regressões realizadas.

TABELA 4. Índices de determinação, betas padronizados e graus de significância de quatro regressões múltiplas realizadas para o teste de mediação entre as variáveis do modelo investigado.

\begin{tabular}{|c|c|c|c|c|c|}
\hline & $\begin{array}{l}\text { Variável } \\
\text { critério }\end{array}$ & $\begin{array}{l}\text { Variáveis } \\
\text { preditoras }\end{array}$ & $\mathrm{R}^{2}$ ajustado & $\begin{array}{l}\text { Significância do } \\
\text { modelo }\end{array}$ & $\square$ \\
\hline Regressão 1 & $\begin{array}{l}\text { Bem-estar no } \\
\text { trabalho }\end{array}$ & $\begin{array}{l}\text { Satisfação com } \\
\text { os suportes } \\
\text { organizacionais }\end{array}$ & 0,569 & $<0,001$ & $\begin{array}{l}\text { Valores entre } \\
0,039 \text { (NS) a } \\
0,500^{*}\end{array}$ \\
\hline Regressão 2 & $\begin{array}{l}\text { Bem-estar no } \\
\text { trabalho }\end{array}$ & Resiliência no trabalho & 0,170 & $<0,001$ & $0,419(S)$ \\
\hline Regressão 3 & $\begin{array}{l}\text { Resiliência no } \\
\text { trabalho }\end{array}$ & $\begin{array}{l}\text { Satisfação com } \\
\text { os suportes } \\
\text { organizacionais }^{\star *}\end{array}$ & 0,044 & 0,026 & $\begin{array}{l}\text { Valores entre } \\
0,009 \text { a } 0,198 \\
\text { (NS) }\end{array}$ \\
\hline Regressão 4 & $\begin{array}{l}\text { Bem-estar no } \\
\text { trabalho }\end{array}$ & $\begin{array}{l}\text { Satisfação com } \\
\text { os suportes } \\
\text { organizacionais }{ }^{* * *} \text { e } \\
\text { resiliência no trabalho }\end{array}$ & 0,617 & $<0,001$ & $\begin{array}{l}\text { Valores entre } \\
0,230 \text { e } 0,512 \\
\text { (S) }\end{array}$ \\
\hline
\end{tabular}

\section{Notas:}

(S) para Significativo e (NS) para não significativo.

*Apenas satisfação com suporte organizacional e satisfação com o suporte social material são significativos.

${ }^{* *}$ Não há valores significativos para os betas padronizados.

***Apenas satisfação com suporte organizacional e satisfação com o suporte social material são significativos.

A Tabela 4 mostra os resultados encontrados nas quatro regressões múltiplas necessárias para o teste do poder mediacional da variável resiliência no trabalho na determinação das variáveis de satisfação com os suportes organizacionais sobre o bem-estar no trabalho (Baron \& Kenny, 1986; Ribeiro, 2012). Na primeira regressão, em atendimento à primeira condição dos autores, foram posicionadas as quatro variáveis relativas às satisfações com os suportes organizacionais como regressoras da variável bem-estar no trabalho.

Os resultados indicam que, como conjunto, as quatro variáveis possuem um índice de determinação significativo $\left(R^{2}=0,569 ; F(4,154)=35,0852 ; p<0,001\right)$. Porém, apenas satisfação com suporte organizacional 
$(\beta=0,500 ; t=5,842 ; \mathrm{p}<0,001)$ e satisfação com o suporte social material $(\beta=0,208 ; t=2,729 ; \mathrm{p}=0,007)$ contribuem de forma significativa na explicação da variável critério.

$\mathrm{Na}$ segunda regressão, ainda em atendimento aos critérios descritos pelos autores, resiliência no trabalho foi posicionada como regressora da variável bem-estar. Os resultados indicam que a variável antecedente possui índices de determinação significativos $\left(\mathrm{R}^{2}=0,170 ; \mathrm{F}(1,157)=33,348 ; \mathrm{p}<0,001 ; \beta=0,419 ; t=5,775 ; \mathrm{p}<0,001\right)$, embora frágeis.

$\mathrm{Na}$ terceira regressão, em atendimento ao terceiro critério, as satisfações com os suportes organizacionais foram posicionados como regressores da variável resiliência no trabalho. Tal como já havia acontecido na primeira regressão, quando posicionadas as quatro variáveis, o modelo mostra índices de determinação significativos $\left(\mathrm{R}^{2}=0,44 ; \mathrm{F}(4,154)=2,807 ; \mathrm{p}=0,028\right)$. Contudo, nenhuma das variáveis, isoladamente, contribui de maneira significativa na explicação da variável critério. Não foram encontrados índices significativos de Beta. Assim, o terceiro critério de mediação proposto por Baron e Kenny, em 1986, e por Ribeiro (2012) não foi satisfeito, indicando que a relação entre as satisfações com os suportes organizacionais com o bem-estar no trabalho não é mediada pela resiliência no trabalho.

Impõe-se um impasse para o estudo. Embora não tenham sido encontradas contribuições significativas entre as variáveis exploradas na terceira regressão, o modelo foi significativo, próximos do limite. Ou seja, em bloco, a variância das satisfações com os suportes organizacionais explicam a variância de resiliência no trabalho.

Com essas evidências e, embora os dados já indicassem a inexistência de mediação entre as variáveis do modelo, uma quarta regressão foi realizada. Nela, foram posicionadas as variáveis satisfações com o suporte organizacional e satisfação com o suporte social material (significativos na primeira regressão) e resiliência no trabalho com regressoras de bem-estar no trabalho (quarto critério para verificação da relação mediativa entre as variáveis do modelo). Os resultados indicam que as variáveis, como um bloco, encontram significância na explicação da variável critério $\left(\mathrm{R}^{2}=0,617 ; \mathrm{F}(3,155)=85,923 ; \mathrm{p}<0,001\right)$ e que as três variáveis regressoras contribuem significativamente para tal (satisfação com suporte organizacional $-\beta=0,512 ; t=7,283 ; \mathrm{p}<0,001$ - satisfação com suporte social material $-\beta=0,230 ; t=3,321 ; p=0,001$ - resiliência no trabalho $-\beta=0,244$; $\mathrm{t}=4,791 ; \mathrm{p}<0,001)$.

Como já anunciado na terceira regressão, a relação entre as satisfações com os suportes organizacionais e o bem-estar no trabalho não é mediada pela resiliência no trabalho, já que, nessa regressão, o poder de explicação das primeiras (satisfações com os suportes organizacionais) não decresce quando do acréscimo de resiliência no trabalho à regressão - condição essencial proposta por Baron e Kenny (1986) e por Ribeiro (2012). Pelo contrário, cresce. Assim, é mais razoável supor que as variáveis posicionadas na quarta regressão contribuem de maneira significativa na explicação do bem-estar, mas de modo não sequenciado. Ou seja, quando em suas presenças, o empregado relata bem-estar no trabalho, mas o poder de explicação das satisfações com os suportes organizacionais não dependem dos níveis relatados de resiliência no trabalho. As implicações desses resultados e uma agenda de pesquisa sugerida a partir delas serão discutidas a seguir.

\section{CONSIDERAÇÕES FINAIS}

Este estudo objetivou testar a mediação da variável resiliência no trabalho entre as variáveis satisfação com suportes organizacionais (organizacional e sociais no trabalho) e bem-estar no trabalho. O modelo proposto teve como referenciais os pressupostos da psicologia positiva que, a partir de seu advento, busca investigar aspectos positivos na estruturação e no desenvolvimento humano. Neste domínio, surge a concepção de bemestar que, no âmbito do trabalho, ganha especial importância, dado que a condição de trabalhador sempre conferiu ao indivíduo a condição de um sujeito submetido a situações adversas.

Neste trabalho, buscou-se a verificação, demonstrada pela literatura, de que variáveis pessoais e organizacionais seriam bons preditores do bem-estar no trabalho. Mas o modelo proposto não se confirmou. A satisfação com os suportes organizacionais são antecedentes consistentes do bem-estar em ambientações corporativas, mas não dependem dos níveis de resiliência, como foi dado como hipótese aqui.

Quatro hipóteses explicativas podem ser aventadas. A primeira diz respeito à natureza das variáveis pesquisadas. Satisfação (no trabalho ou com suportes) é uma variável de caráter afetivo ou atitudinal, enquanto resiliência é, essencialmente, uma variável de caráter avaliativo, portanto, cognitivo. A primeira é um sentimento direcionado a aspectos diretamente relacionados a condições organizacionais e do trabalho, 
enquanto a segunda é uma avaliação de condições individuais. A natureza e o direcionamento das medidas podem ter influenciado os resultados. Portanto, essa é uma agenda rica para pesquisadores no futuro.

A segunda hipótese explicativa para os resultados encontrados diz respeito à temporalidade das variáveis investigadas como preditoras. Satisfações são variáveis temporais sujeitas a mudanças conforme as condições externas aos indivíduos. Por outro lado, resiliência, como assumida neste estudo, é definida como variável com características estáveis, pouco influenciada por condições externas ao indivíduo, cuja avaliação tende a ser minimamente atemporal. Testar se as naturezas temporais das variáveis investigadas, principalmente se posicionadas em modelos de predição ou explicação, também constitui uma agenda que pode ser incorporada em pesquisas futuras.

A terceira hipótese explicativa para os resultados deste estudo refere-se ao posicionamento das variáveis antecedentes do modelo. Há algum tempo, a literatura vem demonstrando que cognições antecedem aos afetos (Gomide \& Hernandes, 2005; Gondim \& Siqueira, 2004; Siqueira, 1995), e o posicionamento dos antecedentes no modelo proposto inverte essa lógica. Assim, o modelo proposto posiciona afetos (satisfações) como antecedentes de uma cognição (resiliência). Como o modelo não se confirmou, parecem se reafirmar os achados anteriores relatados. Como hipóteses sempre necessitam de investigação para suas confirmações ou refutações, esta se torna o terceiro ponto para uma agenda futura de pesquisas.

A quarta hipótese explicativa também remete a achados anteriores da literatura, que têm afirmado que variáveis pessoais, quando comparadas a variáveis organizacionais, têm poder preditor menor para variáveis relacionadas a ambientes organizacionais (por exemplo, desempenho). Essa hipótese parece estar confirmada por este estudo.

Por fim, sugere-se a ampliação do escopo deste estudo, tanto na investigação de novas variáveis na pesquisa dos antecedentes de bem-estar no trabalho como na investigação de um contingente mais amplo de trabalhadores.

\section{REFERÊNCIAS}

Barlach, L., Limongi-França, A. C. \& Malvezzi, S. (2008). O conceito de resiliência aplicada ao trabalho. Revista Interamericana de Psicologia, 42(1), 101-112.

Baron, R., \& Kenny, D. A. (1986). The moderator-mediator variable distinction in social psychological research: conceptual, strategic, and statistical considerations. Journal of Personality and Social Psychology, 51(6), 1173-1182. doi: 10.1037/00223514.51.6.1173

Batista, R. L., \& Oliveira, A. F. (2008). Validação da escala de resiliência para o contexto organizacional. Florianópolis, Sessão de pôster apresentada no III Congresso Brasileiro de Psicologia Organizacional e do Trabalho. Recuperado em 07 novembro, 2008, de http://www.sbpot.org.br/iiicbpot/trabalhos/1297.htm

Batista, R. L., \& Oliveira, A. F. (2012). Antecedentes da Confiança do Empregado na Organização. Estudos de Psicologia, 17(2), 247-254. doi: 10.1590/S1413-294X2012000200008

Bennis, W. G. (1962). Changing organization: Essays on the development and evolution of human organizational. New York: Mc Graw-Hill.

Carvalho, V. D., Borges, L. O., Vikan, A., \& Hjemdal, O. (2011). Resiliência e socialização organizacional entre servidores públicos brasileiros e noruegueses. Revista de Administração Contemporânea, 15, 815-833.

Day, C., \& Gu, Q. (2007). Variations in the conditions for teachers' professional learning and development: Sustaining commitment and effectiveness over a career. Oxford Review of Education, 33(4), 423-443. doi:10.1080/03054980701450746

Ferreira, M. C. (2012). Qualidade de vida no trabalho: uma abordagem centrada no olhar dos trabalhadores. Brasília: Paralelo 15.

Ferreira, M. C., Souza, M. A., \& Silva, C. A. (2012). Qualidade de vida e bem-estar no trabalho: principais tendências e perspectivas teóricas. In M. C. Ferreira, \& H. Mendonça (Orgs.). Saúde e Bem-estar no Trabalho (pp. 79-104). São Paulo: Casa do Psicólogo.

Gomide, S., Jr., \& Hernandez, J. D. (2005). Bem-estar no trabalho: os estudos realizados na Universidade de Uberlândia. Revista da Sociedade de Psicologia do Triângulo Mineiro, 9(1), 02-08.

Gomide, S., Jr., Guimarães, L. C., \& Damásio, L. F. Q. (2004). Construção e validação de um instrumento de medida de percepção de suporte social no trabalho. I/ Seminário de Pesquisa do Grupo Interinstitucional de Pesquisa em Bem-estar, Suporte Social e Trabalho. Uberlândia, MG. 
Gomide, S., Jr., \& Nascimento, J. O. (2012). A Saúde das organizações. In M. C. Ferreira, \& H. Mendonça (Orgs.). Saúde e Bemestar no Trabalho (pp. 131-156). São Paulo: Casa do Psicólogo.

Gondim, S. M. G. \& Siqueira, M. M. (2004). Emoções e Afetos no Trabalho. In J. C. Zanelli, J, E. Borges-Andrade, \& A. V. B. Bastos (Orgs). Psicologia, Organizações e Trabalho no Brasil (pp. 207-236). Porto Alegre: Artmed.

Harter, J. K., Schmidt, F. L., \& Keyes, C. L. (2002). Well-being in the workplace and its relationship to business outcomes: a review of the gallup studies. In C. L. Keyes, \& J. Haidt (Orgs.). Flourishing: The positive person and the good life (pp. 205-224). Washington D.C.: American Psychological Association.

Hernandez, J. (2007). Impactos da Percepção de Saúde Organizacional no bem-estar no Trabalho. Dissertação de mestrado, Universidade Federal de Uberlândia, Uberlândia, MG, Brasil.

Hjemdal, O., Roazzi, A., Dias, M. G. B. B., Roazzi, M., \& Vikan, A. (2009). Exploring the psychometric properties of the resilience scale for adults in a Brazilian sample. In D. Elizur, \& E. Yaniv (Orgs.). Facet new horizons in theory construction and data analysis (pp. 120-138). Jerusalem: FTA.

Jaffe, D. T. (1995). The healthy company: research paradigms for personal and organizational health. In S. L. Sauter, \& L. R., Murphy (Eds.). Organizational risk factors for job stress. Washington DC: APA.

Job, F. P. P. (2003). Os Sentidos do Trabalho e a Importância da Resiliência nas Organizações. Tese de doutorado, Escola de Administração de Empresas, Fundação Getúlio Vargas, São Paulo, Brasil.

Keyes, C. L. M. Hysom, S. J., \& Lupo, K. L. (2000). The positive organization: leadership legitimacy, employee well-being, and the bottom line. The Psychologist-Manager Journal, 4(2), 143-153.

Lopes, V. R., \& Martins, M. C. F. (2011). Validação fatorial da escala de resiliência de Connor-Davidson (Cd-Risc-10) para brasileiros. Revista Psicologia: Organizações e Trabalho, 11(2), 36-50.

Martins, M. C. F., Siqueira, M. M. M., Pieroni, J. P., Zampieri, R. (2012). Percepções de Suporte e Afetos na Explicação de Resiliência Pessoal: um estudo com trabalhadores. Rio de Janeiro, Sessão de pôster apresentada no V Congresso Brasileiro de Psicologia Organizacional e do Trabalho. Recuperado em 24 março, 2014, de http://www.sbpot.org.br/vcbpot/ trabalhos/trabalho_aprovado.php.htm

Maslow, A. H. (1954). Motivation and personality. New York: Harper \& Brothers.

Mendonça, H., Ferreira, M. C., Porto, J., \& Zanini, D. S.(2012). Saúde, qualidade de vida e bem-estar: limites e interfaces teóricometodológicas. In M. C. Ferreira, \& H. Mendonça (Orgs.). Saúde e Bem-estar no Trabalho (pp. 11-34). São Paulo: Casa do Psicólogo.

Miles, J., \& Shevlin, M. (2001). Applying regression and correlation - a guide to students and researchers. London: Sage.

Paz, M. G. T. (2005). Bem-estar pessoal nas organizações: construção e validação de um instrumento de medida. Universidade Católica de Brasília, Brasília. Texto não publicado.

Paz, M. G. T. (2011). Perfil cultural de las organizaciones e bienestar del trabajador. In E. Agulló, J. L. Álvaro, A. Garrido, R. Medina, \& I. Schweiger (Orgs.). Nuevas formas de organización del trabajo y la empleabilidad (pp.85-108). Orviedo: Servicio de Publicaciones Universidad de Oviedo.

Paz, M. G. T., Neiva, E. R., \& Dessen, M. C. (2012). Bem-estar e felicidade nas organizações: um só fenômeno? In M. C. Ferreira, \& H. Mendonça (Orgs.). Saúde e bem-estar no trabalho (pp. 105-130). São Paulo: Casa do Psicólogo.

Ribeiro, P. E. C. D. (2012). Qualidade de vida organizacional: o impacto das configurações de poder e o papel mediador da justiça organizacional. Dissertação de mestrado, Universidade de Brasília, Brasília, DF, Brasil.

Rocha Sobrinho, F., \& Porto, J. B. (2012). Bem-estar no trabalho: um estudo sobre suas relações com clima social, coping e variáveis demográficas. Revista de Administração Contemporânea, 16(2), 253-270. doi:10.1590/S1415-65552012000200006

Sant'Anna, L. L., Paschoal, T., \& Gosendo, E. (2012). Bem-estar no trabalho: relações com estilos de liderança e suporte para ascensão, promoção e salários. Revista de Administração Contemporânea, 16(5), 744- 764. doi: 10.1590/S141565552012000500007

Seligman, M. E. P., \& Csikszentmihalyi, M. (2000). Positive psychology: an introduction. American Psychologist, 55, 5-14. doi: 10.1037/0003-066X.55.1.5

Siqueira, M. M. M., \& Padovam, V. A. R. (2008). Bases teóricas de bem-estar subjetivo, bem-estar psicológico e bem-estar no trabalho. Psicologia: Teoria e Pesquisa, 24(2), 201-209. doi: 10.1590/S0102-37722008000200010

Siqueira, M. M. M. (1995). Antecedentes e consequentes do comportamento de cidadania organizacional: a análise de um modelo pós-cognitivo. Tese de doutorado, Universidade de Brasília, Brasília, DF, Brasil.

Soraggi, F., \& Paschoal, T. (2011). Relação entre bem-estar no trabalho, valores pessoais e oportunidades de alcance de valores pessoais no trabalho. Estudos e Pesquisas em Psicologia, 11(2), 314-632. 